\title{
RANCANG BANGUN DECISION SUPPORT SYSTEM UNTUK PEMILIHAN RUTE PENGIRIMAN PAKET PADA PERUSAHAAN PENYEDIA JASA LOGISTIK
}

\author{
Bilal Ahmadi, Devi Jayawati \\ Politeknik APP Jakarta
}

Received: July 20, 2017; Accepted: October 31, 2017; Published: November 30, 2017

\begin{abstract}
Traveling Salesman Problem (TSP) is a well-known route optimization problem in which a set of customers is visited only once and all demands are satisfied within single route. Package delivery by a courier company can be considered into this type of problem. While many of the previous research had been conducted, the application of the solutions were limited due to unreal distance measure. This paper developed a decision support system for route optimization using free online maps from Google and Google Maps Application Programming Interface (API). Genetic Algorithm was employed to generate solutions within relatively short time. Furthermore, the solutions was viewed as a function of distance and time. There were some limitations from Google in case of acquiring distance data with the free of charge mechanism. Future research can tackle this backdraw by putting more customer points. Other heuristic methods could also be used for comparison purpose.
\end{abstract}

Keywords: traveling salesman problem, google maps, google maps API, genetic algorithm

\begin{abstract}
ABSTRAK
Permasalahan optimasi dalam pemilihan rute salah satunya dikenal dengan istilah Traveling Salesman Problem (TSP). Bentuk nyata dari tipe permasalahan ini dapat dilihat pada perusahaan penyedia jasa logistik, yaitu pada layanan pengiriman paket. Pada aktivitas tersebut, kurir dibekali dengan sejumlah paket yang harus dikirim kepada sejumlah pelanggan di suatu area tertentu. Pada umumnya kurir akan memilih rute urutan pelanggan yang dikunjungi sesuai dengan pengetahuan yang ia miliki. Penelitian ini merancang suatu aplikasi decision support system (sistem penunjang pengambilan keputusan) dalam hal pemilihan rute dengan mempertimbangkan total waktu tempuh minimum. Aplikasi yang dibangun menggunakan data yang terdapat pada Google Maps, suatu layanan peta online tidak berbayar dari Google Inc., dan diintegrasikan dengan Google Maps API (Application Programming Interface). Hasil pengujian menunjukkan metode Genetic Algorithm (GA) dapat memecahkan permasalahan TSP dalam pemilihan rute pengiriman paket pada perusahaan penyedia jasa logistik, meskipun masih terdapat keterbatasan titik lokasi yang dipertimbangkan. Kecepatan iterasi memberikan solusi yang relatif cepat dan nyata sesuai dengan kondisi di lapangan. Penelitian selanjutnya dapat diarahkan pada peningkatan jumlah titik yang dipertimbangkan. Selain itu dapat pula digunakan metode heuristik lainnya untuk membandingkan hasil algoritma GA yang diperoleh pada penelitian ini.
\end{abstract}

Kata kunci: traveling salesman problem, google maps, google maps API, genetic algorithm 


\section{PENDAHUluan}

Pertumbuhan transaksi perdagangan melalui media online (e-commerce) menjadi salah satu faktor yang mendorong semakin berkembangnya industri penyedia jasa logistik. Aktivitas logistik, diantaranya pergudangan, pengelolaan persediaan, dan pengiriman barang, menjadi tulang punggung dari kegiatan $e$ commerce.

Diantara aktivitas logistik pada bisnis $e$ commerce adalah pengiriman barang pesanan pelanggan. Proses ini menjadi hal yang krusial karena beberapa karakteristik yang dimilikinya. Pertama adalah karena proses pengiriman akan menentukan sampai tidaknya barang pesanan kepada pelanggan, baik dalam hal ketepatan maupun kecepatan. Kedua, biaya-biaya terkait pengiriman, misalkan biaya bahan bakar, kurir, perawatan armada transportasi dan lain-lain, adalah biaya-biaya yang dapat dikendalikan apabila direncanakan dengan baik. Ketiga, aktivitas transportasi merupakan aktivitas logistik dengan persentase biaya terbesar diantara aktivitas logistik lainnya. Dengan demikian, peningkatan yang berkesinambungan (continuous improvement) pada aktivitas transportasi, dalam hal ini pengiriman barang pesanan pelanggan, akan memperbaiki efisiensi operasional perusahaan.

Aktivitas pengiriman barang pesanan pelanggan seperti diatas dapat dikategorikan ke dalam permasalahan Traveling Salesman Problem (TSP). Secara umum TSP dapat didefinisikan sebagai permasalahan yang bertujuan untuk mencari cara termurah (atau terpendek jaraknya) dalam mengunjungi sejumlah titik (pelanggan), masing-masing hanya sekali, dan kemudian kembali ke titik awal (depo/pabrik/gudang) (Applegate dkk, 2007:1).

Penelitian ini bertujuan untuk merancang suatu sistem penunjang pengambilan keputusan (decision support system) dalam hal penentuan rute pengiriman barang pesanan pelanggan pada perusahaan penyedia jasa logistik. Aspek keputusan yang dipertimbangkan adalah urutan pelanggan yang dikunjungi dengan total jarak yang ditempuh menjadi minimal. Perbedaan permasalahan yang diangkat dalam penelitian ini dengan literatur TSP yang ada sebelumnya adalah pada parameter jarak antar titik pelanggan. Pada bentuk baku TSP, jarak antar titik pelanggan merupakan jarak Euclidean, yakni jarak terpendek dari dua titik yang dihubungkan dengan garis lurus. Sedangkan jika dilihat secara riil pada aktivitas transportasi, maka nilai jarak ini bisa menjadi tidak valid, salah satunya misalkan karena tidak ada jalan penghubung langsung antar kedua titik tersebut. Dengan mempertimbangkan hal tersebut, maka pada penelitian ini diperhitungkan jarak sesungguhnya yang akan dilalui oleh kurir dalam mengunjungi tiap titik pelanggan. Untuk memperoleh data jarak tersebut digunakan bantuan aplikasi Google Maps yang memetakan daerah pengiriman sesuai dengan kondisi riil yang ada. Fitur yang tersedia dalam Google Maps terbatas pada optimasi jarak point to point, bukan jarak tempuh total dari multiple point secara bersamaan. Oleh karena itu diperlukan perhitungan dengan menggunakan algoritma heuristik untuk menentukan urutan pelanggan yang akan dikunjungi sehingga meminimalkan jarak tempuh total dari rute pengiriman tersebut. Pada penelitian ini rute pengiriman dibatasi hanya untuk rute pangiriman jalur darat. Beberapa asumsi digunakan dalam penelitian ini. Pertama, jenis layanan pengiriman barang yang diantar bersifat homogen. Kedua, pelanggan selalu berada di tempat ketika barang tiba di tempat tujuan. Ketiga, tidak terdapat kesalahan pada alamat pelanggan maupun jenis dan kuantitas barang yang dikirim. Keempat, kurir kembali ke titik awal (depo/pabrik/gudang) setelah mengunjungi pelanggan terakhir 
Penelitian ini terdiri dari empat bagian. Bagian pertama pendahuluan, kemudian diikuti dengan metode penelitian, hasil dan pembahasan, serta pada bagian akhir ditutup dengan kesimpulan.

\section{METODE PENELITIAN}

Bagian ini menjelaskan tahapan yang ditempuh dalam penelitian. Tahap awal yang dilakukan adalah studi pendahuluan. Studi pendahuluan mencakup beberapa kegiatan perencanaan seperti studi pustaka, perumusan masalah dan tujuan penelitian, serta perancangan metode penelitian. Tahap lanjutan setelah studi pendahuluan adalah rancang bangun sistem. Pada tahapan ini terdapat beberapa hal yang dilakukan yaitu penyusunan model TSP, integrasi model dengan Google Maps, serta pembuatan rancang bangun sistem penunjang pengambilan keputusan. Penyusunan rancang bangun sistem menggunakan algoritma heuristik untuk menentukan rute optimal yang meminimumkan jarak tempuh pengiriman. Tahap selanjutnya adalah pengujian model dan sistem. Setelah sistem selesai dibangun, maka dilakukan pengujian model dan sistem dengan menggunakan dua jenis data. Data pertama adalah data set benchmark permasalahan TSP untuk menguji validitas dari model. Setelah didapatkan model yang valid, maka model diimplementasikan pada permasalahan riil yang dihadapi oleh perusahaan. Hasil dari pengujian model dan sistem ini kemudian dianalisis lebih lanjut untuk ditentukan kesimpulan yang dapat diambil. Setelah semua proses analisis selesai dilakukan, maka langkah terakhir adalah penarikan kesimpulan dari penelitian yang telah dilaksanakan. Saran-saran untuk pengembangan penelitian ke depan juga disampaikan pada tahapan ini. Tahapan penelitian secara keseluruhan disajikan pada gambar 3.1.

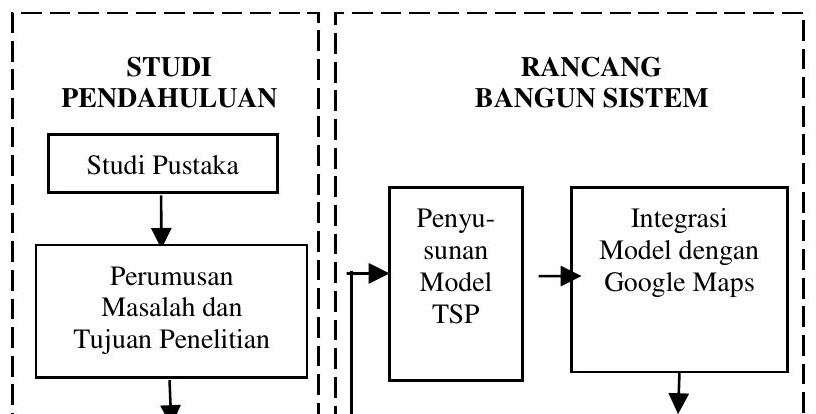

Gambar 3.1 Skema tahapan penelitian

\section{IMPLEMENTASI}

Beberapa hal yang akan diuraikan pada bagian ini diantaranya: (i) penyusunan model TSP, (ii) penyelesaian TSP dengan algoritma GA, dan (iii) implementasi GA pada permasalahan TSP menggunakan Goggle Maps API.

\section{a. Penyusunan Model TSP}

Dalam penghantaran barang, kurir dapat memilih urutan perjalanan dalam menghantarkan barang ke semua alamat tujuan sebanyak masing-masingnya satu kali kunjungan dan kembali lagi ke alamat asal (PT.JNE). Hal ini dapat disajikan dalam persamaan berikut: 


$$
\begin{gathered}
V=\left\{v_{0}, v_{1}, \ldots, v_{n}\right\} \\
|V|=N+1 \\
w_{v_{a}, v_{b}}=w_{a}=d_{a, b}, e \in E, \\
\operatorname{dimana} E=\left\{\left(v_{a}, v_{b}\right): v_{a}, v_{b} \in V\right\} \\
W=\left\{\left\{d_{a b}\right\}_{N+1 \times N+1}\right\}
\end{gathered}
$$

$V$ menyatakan himpunan titik lokasi yang terdiri dari titik asal yaitu PT. JNE dan titik-titik tujuan penghantaran paket. Sementara $N$ menunjukkan jumlah lokasi tujuan. W adalah matriks jarak dan $d$ adalah jarak antara dua titik lokasi yang dalam hal ini dijadikan sebagai bobot untuk tiap busur perjalanan yang terbentuk. Tujuan yang ingin dicapai dari persoalan TSP pada permasalahan ini adalah agar jumlah bobot dari tiap busur yang menghubungkan simpul (alamat tujuan) menjadi minimal. Permasalahan ini termasuk dalam kategori aTSP (asymmetric TSP), dimana jarak antara dua lokasi yang sama dalam penghantaran barang bisa berbeda jika titik awalnya berbeda $w_{v_{a}, v_{b}} \neq w_{v_{b}, v_{a}}$.

\section{b. Penyelesaian TSP dengan Algoritma GA}

Algoritma GA merupakan metode pencarian dan optimasi yang meniru teori evolusi yang dikemukakan oleh Darwin. Jika dalam seleksi alam individu yang kuat dapat bertahan dalam proses evolusi maka begitu juga halnya pada GA kromosom yang dapat bertahan hidup adalah individu dengan nilai fitness yang tinggi. Pada penelitian ini digunakan algoritma GA untuk memperoleh kombinasi terbaik dari jalur yang akan dilalui dengan waktu tempuh yang cepat dan dapat melayani semua penugasan lokasi pengiriman paket. Adapun tahapan dari metode GA meliputi pengkodean kromosom, inisialisasi populasi, perhitungan nilai fitness, seleksi, crossover, serta mutasi. Data inputan yang diperlukan sebagai berikut:

a. Data jarak tiap lokasi penghantaran barang
Berikut contoh data jarak untuk empat alamat pengiriman barang:

$$
\mathrm{W}=\left[\begin{array}{lllll}
0 & 5 & 7 & 7 & 4 \\
6 & 0 & 2 & 2 & 1 \\
7 & 2 & 0 & 3 & 2 \\
7 & 1 & 3 & 0 & 2 \\
3 & 1 & 2 & 3 & 0
\end{array}\right]
$$

b. Nilai probabilitas crossover $\left(\mathrm{p}_{\mathrm{c}}\right)$. Nilai $\mathrm{p}_{\mathrm{c}}$ yang ditetapkan pada penelitian ini adalah 0.5

c. Nilai probabilitas mutasi. $\left(\mathrm{p}_{\mathrm{m}}\right)$. Nilai $\mathrm{p}_{\mathrm{m}}$ yang ditetapkan pada penelitian ini adalah sebesar 1/N dengan $\mathrm{N}$ adalah jumlah alamat tujuan pengiriman barang.

Kriteria penghentian yang digunakan adalah jumlah generasi (maksimum iterasi).

Dalam tahap pengkodean kromosom, dilakukan pemberian kode pada gen yang membentuk kromosom. Data inputan pada tahap ini adalah alamat pengiriman barang yang akan dikunjungi oleh kurir PT. JNE. Tiap gen merepresentasikan alamat tujuan pengiriman barang termasuk alamat asal (PT. JNE). Pengkodean dilakukan dengan memberi nomor urut sebanyak jumlah alamat tujuan+1, yakni dari $1 \mathrm{~s} / \mathrm{d} \mathrm{N}+1$, dimana $\mathrm{N}$ $=$ jumlah alamat tujuan. Berikut contoh pengkodean kromosom untuk 4 alamat tujuan pengiriman barang:

Kromosom [1] $=\left[\begin{array}{llll}3 & 4 & 2 & 5\end{array}\right]$

Ket : $\quad 1=$ titik awal penghantaran barang (kantor JNE)

$$
\begin{aligned}
& \text { 2= Pasar Minggu } \\
& 3=\text { Pejaten } \\
& \text { 4= Jati Padang } \\
& \text { 5= Tanjung Barat }
\end{aligned}
$$

Pengkodean di atas menunjukkan kromosom 1 berisi rute perjalanan kurir dari kantor JNE (angka 1) menuju Pejaten, Jati Padang, Pasar Minggu, Tanjung Barat, dan kembali ke kantor JNE. 
Pada tahap inisialisasi populasi, Penentuan populasi awal dilakukan dengan cara membangkitkan secara acak. Populasi terdiri dari sejumlah gen yang membentuk kromosom. Data inputan yang diperlukan adalah ukuran populasi yaitu jumlah kromosom serta jumlah gen dalam kromosom. Berikut contoh inisialisasi populasi dengan 6 kromosom yang terpilih secara acak:

$$
\begin{aligned}
& \text { Kromosom [1] }=\left[\begin{array}{llll}
3 & 4 & 2 & 5
\end{array}\right] \\
& \text { Kromosom [2] }=\left[\begin{array}{llll}
2 & 3 & 5 & 4
\end{array}\right] \\
& \text { Kromosom [3] }=\left[\begin{array}{llll}
2 & 5 & 3 & 4
\end{array}\right] \\
& \text { Kromosom [4] }=\left[\begin{array}{llll}
4 & 5 & 2 & 3
\end{array}\right] \\
& \text { Kromosom [5] }=\left[\begin{array}{llll}
3 & 2 & 4 & 5
\end{array}\right] \\
& \text { Kromosom [6] }=\left[\begin{array}{llll}
2 & 4 & 3 & 5
\end{array}\right]
\end{aligned}
$$

Nilai Fitness diketahui dari fungsi fitness yang telah didefinisikan sebelumnya pada model TSP. Pada penelitian ini nilai fitness adalah nilai total waktu tempuh dari rute yang dilalui kurir. Nilai fitness:

$$
\begin{aligned}
& f_{1}=\left[\begin{array}{llll}
3 & 4 & 2 & 5
\end{array}\right]=7+3+1+1=12 \\
& f_{2}=\left[\begin{array}{llll}
2 & 3 & 5 & 4
\end{array}\right]=5+2+2+3=12 \\
& f_{3}=\left[\begin{array}{llll}
2 & 5 & 3 & 4
\end{array}\right]=5+1+2+3=12 \\
& f_{4}=\left[\begin{array}{llll}
4 & 5 & 2 & 3
\end{array}\right]=7+2+1+2=12 \\
& f_{5}=\left[\begin{array}{llll}
3 & 2 & 4 & 5
\end{array}\right]=7+2+2+2=13 \\
& f_{6}=\left[\begin{array}{llll}
2 & 4 & 3 & 5
\end{array}\right]=5+2+3+2=12
\end{aligned}
$$

Setelah nilai fitness diketahui, tahapan selanjutnya adalah seleksi. Metode seleksi yang digunakan pada penelitian ini adalah turnamen, yakni dengan membuat beberapa turnamen (pertandingan) antar kromosom berdasarkan nilai fitness yang dimiliki. Pemenang dari tiap turnamen dipilih untuk menjadi generasi baru pada proses selanjutnya. Tingkat kesulitan seleksi dapat disesuaikan dengan mengatur nilai ukuran turnamen (tournament size). Semakin besar ukuran turnamen maka individu yang lemah semakin kecil peluangnya untuk terpilih menjadi generasi selanjutnya.
Dalam tahap crossover, dua induk kromosom dipilih secara acak dalam rangka menghasilkan kromosom baru. Jumlah crossover yang dilakukan didasarkan pada probabilitas crossover $\left(\mathrm{p}_{\mathrm{c}}\right)$ yang telah ditentukan sebelumnya. Pada proses ini dibangkitkan bilangan random $\mathrm{p}$ dengan nilai antara 0 dan 1 . Crossover akan dilakukan ketika nilai random $\mathrm{p}$ $<\mathrm{p}_{\mathrm{c}}$

Metode crossover yang digunakan pada penelitian ini adalah Partial-MappedCrossover. Langkahnya adalah sebagai berikut:

a. Pilih 2 individu kromosom secara acak.

b. Tentukan dua posisi pada kromosom secara acak

c. Lakukan swap (pertukaran) antara 2 induk kromosom induk tersebut

d. Tentukan hubungan pemetaan antara dua daerah pemetaan

e. Tentukan kromosom keturunan berdasarkan hubungan pemetaan pada point (d).

$\mathrm{Pc}=0,5$ artinya diharapkan dalam 1 generasi ada $50 \%$ dari 6 kromosom mengalami crossover (sekitar 3 kromosom). Pilih 3 kromosom secara acak misalkan sbb:

$\mathrm{C}[1]=1$

$\mathrm{C}[2]=3$

$\mathrm{C}[3]=4$

Kromosom [2] = Kromosom [2] $><$ Kromosom [3]

Kromosom [3] = Kromosom [3] $><$ Kromosom [4]

Kromosom [4] = Kromosom [4] $><$ Kromosom [5]

b. kromosom [2]

\begin{tabular}{|l|l|l|l|}
\hline 2 & 3 & 5 & 4 \\
\hline
\end{tabular}

\begin{tabular}{|l|l|l|l|}
\hline 2 & 5 & 3 & 4 \\
\hline
\end{tabular}


Kromosom [3]:

\begin{tabular}{|l|l|l|l|}
\hline 2 & 5 & 3 & 4 \\
\hline
\end{tabular}

\begin{tabular}{|l|l|l|l|}
\hline 4 & 5 & 2 & 3 \\
\hline
\end{tabular}

Kromosom [4]:

\begin{tabular}{|l|l|l|l|}
\hline 4 & 5 & 2 & 3 \\
\hline
\end{tabular}

\begin{tabular}{|l|l|l|l|}
\hline 3 & 2 & 4 & 5 \\
\hline
\end{tabular}

c. kromosom [2]

\begin{tabular}{|l|l|l|l|}
\hline 2 & 5 & 3 & 4 \\
\hline
\end{tabular}

\begin{tabular}{|l|l|l|l|}
\hline 2 & 3 & 5 & 4 \\
\hline
\end{tabular}

Kromosom [3]:

\begin{tabular}{|l|l|l|l|}
\hline 2 & 5 & 2 & 4 \\
\hline
\end{tabular}

\begin{tabular}{|l|l|l|l|}
\hline 4 & 5 & 3 & 3 \\
\hline
\end{tabular}

Kromosom [4]:

\begin{tabular}{|l|l|l|l|}
\hline 4 & 2 & 4 & 3 \\
\hline
\end{tabular}

\begin{tabular}{|l|l|l|l|}
\hline 3 & 5 & 2 & 5 \\
\hline
\end{tabular}

d. Hubungan mapping:

$$
\begin{aligned}
& \text { kromosom [2] : } \longleftrightarrow \gg \quad 3
\end{aligned}
$$

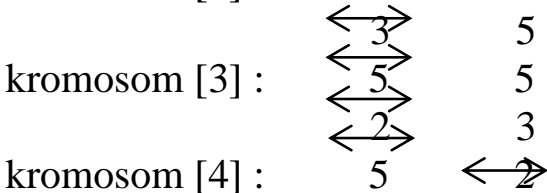

e. Kromosom [2]:

\begin{tabular}{|l|l|l|l|}
\hline 2 & 5 & 3 & 4 \\
\hline 2 & 3 & 5 & 4 \\
\hline
\end{tabular}

Kromosom [3]:

\begin{tabular}{|l|l|l|l|}
\hline 3 & 5 & 2 & 4 \\
\hline
\end{tabular}

\begin{tabular}{|l|l|l|l|}
\hline 4 & 5 & 3 & 2 \\
\hline
\end{tabular}

Kromosom [4]:

\begin{tabular}{|l|l|l|l|}
\hline 5 & 2 & 4 & 5 \\
\hline \multicolumn{4}{|c|}{} \\
\hline 3 & 5 & 2 & 4 \\
\hline
\end{tabular}

Populasi setelah crossover:

Kromosom [1] $=\left[\begin{array}{llll}2 & 3 & 5 & 4\end{array}\right]$

Kromosom [2] $=\left[\begin{array}{llll}2 & 5 & 3 & 4\end{array}\right]$

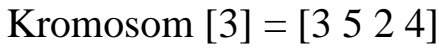

Kromosom [4] $=\left[\begin{array}{llll}5 & 2 & 4 & 5\end{array}\right]$

Kromosom [5] $=\left[\begin{array}{llll}3 & 2 & 4 & 5\end{array}\right]$

Kromosom [6] $=\left[\begin{array}{llll}2 & 4 & 3 & 5\end{array}\right]$

Tahapan yang tidak kalah pentingnya dalam metode GA adalah mutasi. Mutasi berperan untuk menggantikan gen yang hilang pada proses seleksi dan memunculkan kembali gen yang tidak muncul pada tahapan inisialisasi populasi. Metode mutasi yang digunakan adalah swapping mutation, dengan menukarkan nilai gen yang akan ditukar dengan nilai gen yang berada di sebelahnya. Nilai $\mathrm{p}_{\mathrm{m}}$ yang ditetapkan menunjukkan persentase dari jumlah total gen yang mengalami populasi, yakni $1 / 4=0.25$. Artinya 0.25 dari total gen mengalami mutasi yakni sekitar 2. Selanjutnya bangkitkan 2 bilangan random sebagai urutan bilangan gen yang akan dimutasi. 2 bilangan random tersebut misalkan 7 dan 11 sehingga gen yang mengalami mutasi adalah gen ke-7 dan 11. Hasil mutasi sbb:

$$
\begin{aligned}
& \text { Kromosom [1] }=\left[\begin{array}{llll}
2 & 3 & 5 & 4
\end{array}\right] \\
& \text { Kromosom [2] }=\left[\begin{array}{llll}
3 & 4 & 5 & 2
\end{array}\right] \\
& \text { Kromosom [3] }=\left[\begin{array}{llll}
4 & 5 & 3 & 2
\end{array}\right] \\
& \text { Kromosom [4] }=\left[\begin{array}{llll}
3 & 4 & 2 & 5
\end{array}\right] \\
& \text { Kromosom [5] }=\left[\begin{array}{llll}
3 & 2 & 4 & 5
\end{array}\right] \\
& \text { Kromosom [6] = [ [ llll } \left.\begin{array}{lll}
4 & 2 & 3
\end{array}\right]
\end{aligned}
$$

Proses seleksi yang memilih kromosom secara acak berpotensi meninggalkan kromosom dengan nilai fitness yang tinggi. Operator 
crossover juga berpotensi merusak nilai suatu kromosom yang bagus pada awalnya menjadi tidak bagus setelah dikawin silang. Oleh karenanya diperlukan skema untuk mempertahankan kromosom yang memiliki nilai fitness tinggi. Skema tersebut dikenal dengan istilah elitisme. Elitisme menyimpan salinan kromosom tertentu sehingga generasi yang bagus akan tetap dapat diwariskan pada proses selanjutnya.

\section{c. Implementasi GA pada Permasalahan TSP Menggunakan Google Maps API}

Jenis permasalahan TSP yang dibahas pada penelitian ini adalah jasa pengiriman paket pada perusahaan penyedia jasa logistik. Studi terdahulu mayoritas menggunakan titik lokasi berdasarkan koordinat Kartesius (sumbu vertikal dan horizontal) dengan menghitung jarak Euclidean antar titik. Dalam kondisi sebenarnya hal ini tidak sepenuhnya dapat berlaku. Oleh karena itu digunakanlah aplikasi Google Maps API untuk mendapatkan lokasi yang nyata beserta jarak antar lokasi sesuai dengan ketersediaan fasilitas jalan penghubung. Tahapan implementasi GA dengan menggunakan tools Google Maps API digambarkan melalui gambar 4.1 berikut ini

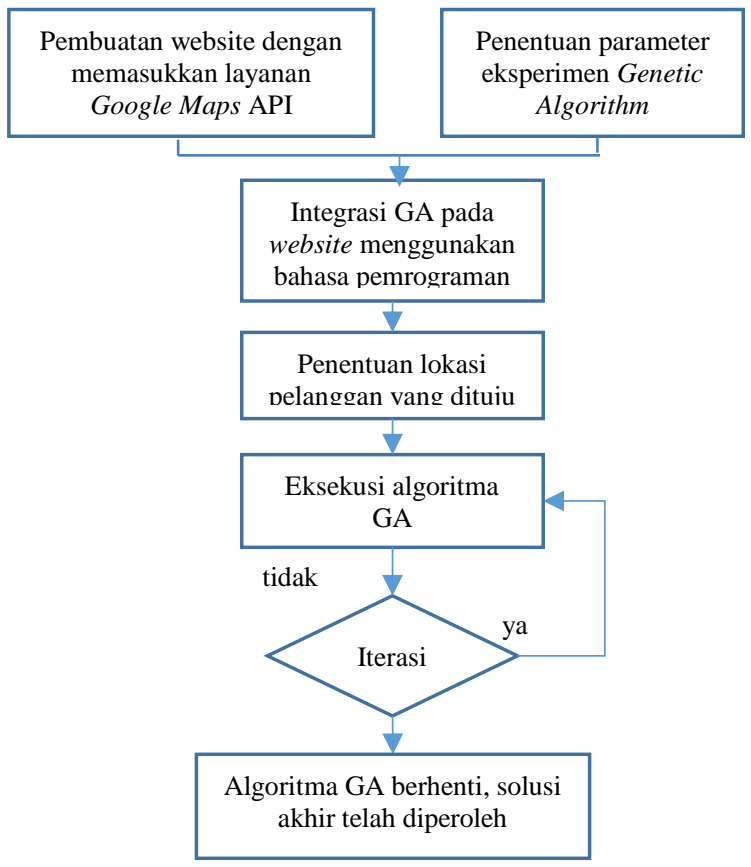

Gambar 4.1. Tahapan implementasi GA menggunakan Google Maps API

Tahap pertama dalam implementasi GA dengan menggunakan tools Google Maps API adalah pembuatan website dengan memasukkan layanan Google Maps API. Untuk dapat memanfaatkan layanan Google Maps API, terlebih dahulu dilakukan permintaan API Key kepada Google agar dapat memperoleh konten yang dimaksud. Penggunaan peta online tersebut bersifat gratis dengan batasan akses tertentu (25.000 kali akses peta dalam satu hari). Setelah mendapatkan API Key maka selanjutnya adalah menentukan titik tengah (center) dari peta sebagai tampilan awal pada website. Penentuan titik tengah tersebut dilakukan secara random. Titik tengah yang dipilih adalah lokasi kampus Politeknik APP Jakarta dengan koordinat latitude dan longitude adalah (-6.3469781, 106.8085342).

Tahap kedua adalah menentukan parameter eksperimen algoritma GA. Parameter yang perlu ditentukan di awal agar algoritma GA dapat dieksekusi adalah ukuran populasi (banyaknya individu/kromosom), ukuran seleksi turnamen, tingkat mutasi, tingkat crossover, elitisme, dan jumlah generasi (dalam hal ini adalah iterasi maksimum). Berdasarkan penelitian terdahulu dan studi literatur yang dilakukan sebelumnya, maka ditentukan nilai dari parameter eksperimen sesuai dengan tabel berikut ini 
Tabel 4.1. Parameter eksperimentasi yang diujikan

\begin{tabular}{|l|c|}
\hline \multicolumn{1}{|c|}{ Parameter } & Nilai \\
\hline Ukuran populasi & 50 \\
\hline Ukuran Turnamen & 5 \\
\hline Tingkat mutasi & 0.1 \\
\hline Tingkar crossover & 0.5 \\
\hline Elitisme & Ya \\
\hline Jumlah generasi & 100 \\
\hline
\end{tabular}

Tahap selanjutnya setelah penentuan parameter eksperimen algoritma GA adalah Integrasi algoritma GA pada website menggunakan bahasa pemrograman JavaScript HTML. Langkah-langkah algoritma GA ditulis dalam bahasa JavaScript, disesuaikan dengan Bahasa pemrograman yang digunakan pada layanan Google Maps API.

Tahapan ke-empat adalah penentuan lokasi pelanggan. Dalam menentukan lokasi pelanggan penerima paket, dipilih titik lokasi yang merupakan fasilitas umum yang memiliki identitas pada google maps. Pada penelitian ini dilakukan pengujian untuk 9 titik lokasi pelanggan sebagai berikut:

Tabel 4.2. Set Lokasi Pelanggan 9 Titik

\begin{tabular}{|c|l|c|}
\hline No. & Nama Lokasi & $\begin{array}{c}\text { Posisi dalam peta } \\
\text { (lat, long) }\end{array}$ \\
\hline 1. & $\begin{array}{l}\text { Politeknik APP } \\
\text { Jakarta }\end{array}$ & $\begin{array}{c}-6.3469781, \\
106.8085342\end{array}$ \\
\hline 2. & $\begin{array}{l}\text { Sekolah Alam } \\
\text { Indonesia }\end{array}$ & $-6.353215,106.80612$ \\
& Cipedak & \\
\hline 3. & Villa Kanaya & -6.352447, \\
& & -6.34306 .814124 \\
\hline 4. & Polimedia & 106.822256 \\
\hline
\end{tabular}

\begin{tabular}{|c|l|c|}
\hline No. & Nama Lokasi & $\begin{array}{c}\text { Posisi dalam peta } \\
\text { (lat, long) }\end{array}$ \\
\hline 5. & Kantor & -6.336879, \\
& Kelurahan & 106.813459 \\
& Ciganjur & \\
\hline 6. & Rumah Sakit & $-6.335898,106.82202$ \\
& Umum Zahirah & \\
\hline 7. & SMP Negeri & -6.330694, \\
& 254 Jakarta & 106.818737 \\
\hline 8. & SMA Negeri 97 & -6.341251, \\
& Jakarta & 106.805605 \\
\hline 9. & Green Andara & -6.319156, \\
& Residence & 106.804082 \\
\hline
\end{tabular}

Tahap ke-lima yaitu eksekusi algoritma GA. Algoritma GA dieksekusi pada sebuah website localhost dengan bantuan software XAMPP. Tampilan dari halaman depan website ditunjukkan oleh gambar 4.2 berikut. Pada halaman depan terdapat menu configuraton, information dan peta berbasis google. Menu configuration berisi pilihan parameter algoritma GA dan metode berkendara template dari google (pilihan kendaraan dan penggunaan jalan tol). Pada menu information nantinya akan berisi jumlah destinasi yang akan dipecahkan oleh algoritma GA.

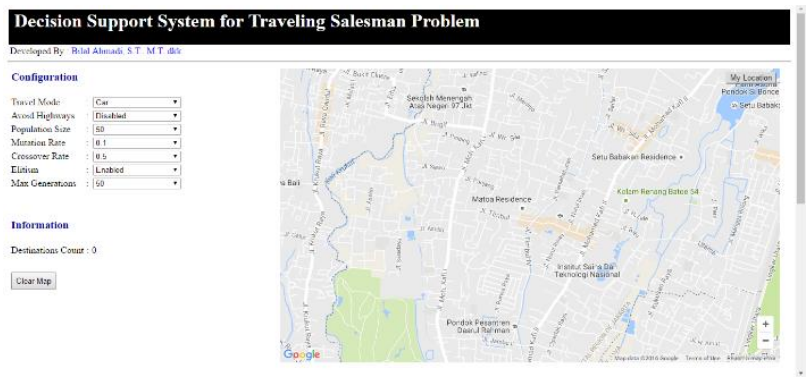

Gambar 4.2. Tampilan halaman depan sistem penunjang keputusan algoritma GA

Untuk mulai memasukkan input titik lokasi pelanggan (destinasi) dilakukan dengan cara melakukan klik pada peta. Hasil input lokasi pelanggan ditunjukkan pada gambar 4.3 berikut 
ini. (destinasi sejumlah 9 namun pada peta terlihat 5 karena faktor zoom pada aplikasi peta)

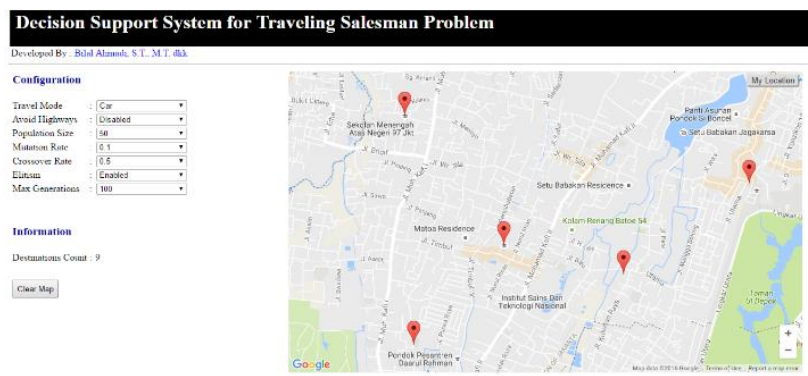

Gambar 4.3. Hasil penandaan (marker) titik lokasi pelanggan

Setelah semua lokasi pelanggan telah tercantum pada peta, maka algoritma GA dapat dijalankan dengan menekan tombol 'Find Best Route' pada bagian bawah tampilan. Hasil dari iterasi algoritma GA ditampilkan pada gambar 4.4. berikut ini.

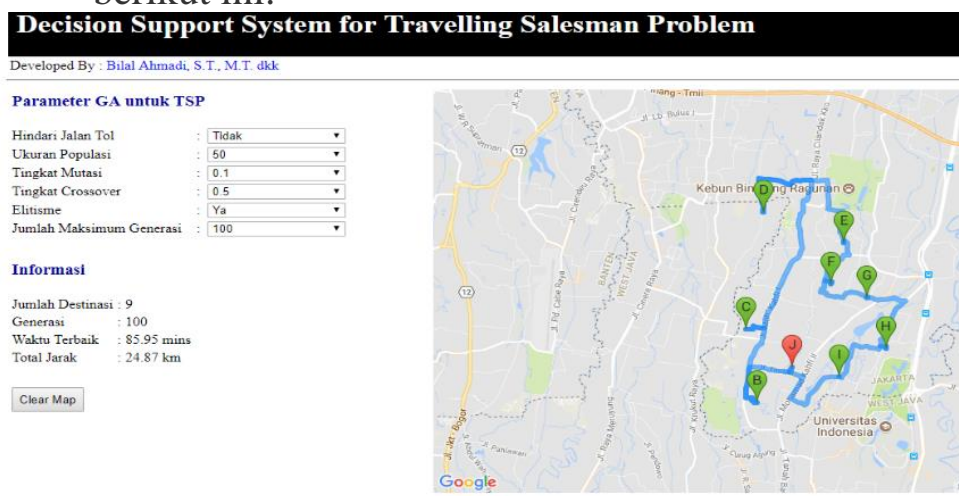

Gambar 4.4. Hasil iterasi algoritma GA

Abjad yang tertera pada hasil iterasi algoritma GA menunjukkan urutan rute. Huruf abjad A dan $\mathrm{J}$ berhimpit pada titik awal yakni kampus Politeknik APP.

Tahapan terakhir adalah analisa hasil eksperimen algoritma GA. Sesuai dengan hasil yang ditampilkan di atas, urutan rute terbaik adalah: Politeknik APP Jakarta - Villa Kanaya -
Polimedia - Rumah Sakit Umum Zahirah - SMP Negeri 254 Jakarta - Green Andara Residence Kantor Kelurahan Ciganjur - SMA Negeri 97 Jakarta - Sekolah Alam Indonesia Cipedak Politeknik APP Jakarta. Total jarak tempuh untuk rute tersebut adalah $24.87 \mathrm{~km}$ dengan waktu tempuh yang dibutuhkan adalah 85.95 menit.

\section{KESIMPULAN}

Berdasarkan eksperimen yang telah dilakukan sebelumnya dapat disimpulkan beberapa hal. Pertama, Genetic Algorithm (GA) merupakan algoritma heuristik yang dapat diaplikasikan pada pemilihan rute pengiriman barang pada perusahaan penyedia jasa logistik. Kedua, pemanfaatan Google Maps API sangat besar manfaatnya untuk membantu pengambilan keputusan dengan menggunakan kondisi nyata (ketersediaan akses jalan, faktor kepadatan lalu lintas, dll) sehingga lebih feasible dalam aplikasi kehidupan sehari-hari. Ketiga, hasil ujicoba algoritma GA dengan menggunakan JavaScript HTML mampu memberikan solusi rute dalam jangka waktu yang relatif cepat dalam hitungan detik. Hal ini dapat lebih ditingkatkan lagi dengan membangun struktur pengkodean yang lebih ringkas dan efektif.

Beberapa saran yang dapat diberikan untuk penelitian lanjutan di masa yang akan datang. Pertama, perlu dilakukan uji dengan jumlah titik yang lebih banyak namun tetap proporsional terhadap kasus nyata yang ada sehari-hari. Selain itu pemanfaatan metode heuristik lainnya juga dapat diselidiki guna membandingkan dengan yang telah diperoleh penelitian ini

\section{DAFTAR PUSTAKA}

[1] Applegate, D.L., Bixby, R.E., Chvátal, V. and Cook, W.J. (2007). The Traveling 
Salesman Problem. Princeton:

Princeton University Press

[2] Arora,S. (1998). Analisis daerah endemik bencana akibat cuaca ekstrim di Sumatera Utara, Journal of the ACM, 45(5), 753-782

[3] Asteria, Clarissa. (2008). Penentuan Rute Distribusi dengan Algoritma Tabu Search untuk VRP dengan Time Windows. Tesis, Universitas Indonesia

[4] Gen M, Cheng R. (2000). Genetic Algorithm and Engineering Optimization. Canada: John Wiley \& Sons, Inc.

[5] Michalewicz Z. (1996). Genetic Algorithms+Data Structures = Evolution Programs. Heidelberg: Springer-Verlag

[6] Purnomo A.C, dkk. (2010). Implementasi Algoritma Greedy pada Layanan Taksi Wisata Berbasis Web, PENS-ITS

[7] Sivanandam S, Deepa S. (2008). Introduction to Genetic Algorithms. New York: Springerverlag Berlin Heidelberg

[8] Toni, D.M. (2009). Penentuan Rute Optimum Jalur Distribusi dalam Supply Chain Network Menggunakan Algoritme Genetika. Skripsi, Institut Pertanian Bogor

[9] Widodo, A.W. dan Mahmudi, W.F. (2010). Penerapan Algoritma Genetika pada Sistem Rekomendasi Wisata Kuliner, Jurnal Ilmiah KURSOR, 4(5), 205-211

[10] Yao, M.J. (2014). Traveling Salesman Problem. Lecture notes in Heuristics. 